\title{
NOMBRARTE: A POESIA DE ALEJANDRA PIZARNIK
}

\author{
RAÚL ANTELO
}

Nombrarte: invocação ao Outro para a evocação do ser. Alteridade radical entre o eu e o tu, precariamente reconciliada pela mediação da palavra. Dessa maneira, a produção de sentido instaura esse Outro, a quem se nomeia, colocando ambos os contendores ombro a ombro. Esse trabalho tem nombre: arte.

Vou tentar mostrar como o trabalho com a lei - o nombre que institui a sociedade; o muro que constrói a cidade - permite pensar a poesia de Alejandra Pizarnik1 como poesia das margens, dos confins, onde o Outro se manifesta, onde o selvagem beira o cultivado não só em oposição dilemática mas também em dialética interpenetração.

Alejandra Pizamik escreveu certa vez que, na poesia moderna, existem dois extremos. O primeiro supõe que tudo é nada, aludindo, talvez, nessa cifra, aos sistemas centrados na poesia social. 0 segundo, entretanto, afirma a desarmonia, o êxtase no reencontro da presença, rotação de signos em homenagem e celebração às bodas do céu e do inferno. É nesta última vertente que se inscreve sua obra.

Lendo Fernando Pessoa em 1962 (ou melhor: Alberto Caeiro), Alejandra coincide com Octavio Paz em que nomear é ser. A palavra que nomeia a pedra não é a pedra mas tem a mesma realidade da pedra, isto porque as palavras não são as coisas mas as pontes que estendemos entre elas e nós. $O$ poeta define-se, portanto, como a consciência das palavras, vale dizer, como a nostalgia da realidade efetiva das coisas.

Enquanto perdura o mito da inocência, Pizarnik busca nombrar las cosas con nombres esenciales, decir la palabra inocente. Receia, mais tarde, em nomear o entorno: ella tiene miedo de no saber nombrar/lo que no existe porque há en el cerebro flores pequeñas/danzando como palabras en la boca de un mudo. O que é esse ir y venir de nombres? O que nele se trama?

Raúl Antelo é professor na Universidade Federal de Santa Catarina.

IAlejandra Pizarnik (Buenos Aires, 1936-1972). Obra: La tierra más ajena (1955); La altima inocencia (1956); Las aventuras perdidas (1958); Arbol de Diana (com prefácio de Oetávio Paz, 1962); Los trabajos y las noches (1965); Extracción de la p،edra de la locuFa (1968); Nombres y flguras (1969); El infierno musical (1971); La condesa sangrienta (1976) Textos de sombra y ultimos poemas (1985). Ensaios esparsos: "E1 poeta desinteresado" (Bobre Yves Bonnefoy, em colaboraçĩo com Ivonne Bordelois, 1962); "Salamandra de Oetavie Paz" (1963); "Alberto Girri: El ojo" (1964); "El verbo encarnado" (lobre Artaud, 1965)| "gilencion en movimiento" (sobre H. A. Murena, 1965); "André Pieyre de Mandiargies! La mereelelera" (1969); "Nota sobre un cuento de Cortázar: Bt ain eiele" (1969) 
Em primeiro lugar, constatamos que o nombre é materialidade. Materialidade corpórea, que prova "Destrucciones":

Del combate con las palabras ocúltame

y apaga el furor de mi cuerpo elemental.

$\hat{\mathrm{E}}$, ainda, materialidade territorial que, à maneira de Bernardo Soares, sendo ponto de fusão e de encontro, só existe através da linguagem:

Yo quería entrar en el teclado para entrar

adentro de la música para tener una patria. (...)

(Tú que fuiste mi única patria, en dónde

buscarte? Tal vez en este poema que voy escribiendo).

Materialidade que, além de efêmera, é contingente, particular. É necessário, no entanto, dar ao nombre uma outra estatura: uma eternidade condicionada - a da arte. Assim soa a voz do Outro ("Tu voz"): Emboscado en mi escritura/ cantas en mi poema./ Rehén de dulce voz/ petrificada en mi memoria. Na descida absoluta e abjeta, Alejandra Pizarnik se depara com $e l$ objeto sin nombre que nace $y$ se pulveriza en el lugar en que el silencio pesa como barras de oro, daí que, além de matéria precária e prisão do fugaz, o nombre se defina como vazio utópico, como silêncio. Nomear é ser. Porém, nomear não é nomear. O nombre é silêncio, sombra projetada atrás de si pelo próprio vazio que é objeto da busca. Alejandra confessa ter partido em busca de quem é. Mas o que é buscar? Buscar - No es un verbo sino un vértigo. No indica acción. No quiere decir ir al encuentro de alguien sino yacer porque alguien no viene. Buscar é jazer: já ser abismal de um sujeito não-sujeito cada vez mais anterior e mínimo, colocado antes e não depois, no baixo e não no alto, longe. Identidade negativa. No sé los nombres. ¿ $A$ quién le dirás que no sabe? Te deseas otra. La otra que eres se desea otra (...) Habla de lo que sabes. Habla de lo que vibra en tu médula y hace luces y sombras en tu mirada, habla del dolor incesante de tus huesos, habla del vértigo, habla de tu respiración, de tu desolación, de tu traición. Es tan oscuro, tan en silencio el proceso a que me obligo. Oh habla del silencio.

Padecendo, como diria Blanchot, dessa impossibilidade de pensar que é o pensamento, em seus "Fragmentos para dominar el silencio", Alejandra repara que la muerte ha restituido al silencio su prestigio hechizante. $Y$ yo no diré mi poema y yo he de decirlo. Aun si el poema (aquí, ahora) no tiene sentido, no tiene destino. Ou, em "Caminos del espejo": Pero el silencio es cierto. Por eso escribo. Estoy sola y escribo. No, no estoy sola. Hay alguien aqui que tiembla. Tudo se tentou (hemos inventado otros nombres) e, no entanto, yo ahora estoy sola.

Nomear foi ser. Agora é não ser.O nombre adquire, desta maneira, plena e pesada imaterialidade. Da mesma forma, na vertigem da busca, a morte não é mais destinação. Morte é já - ser morta: Estaba abrazada al suelo, diciendo un nombre. Creí que me había muerto y que la muerte era decir un nombre sin cesar.

Materialidade afirmada em sua irrisão, a escritura - mero nombre ou talvez silêncio que canta, como prefere Octavio $\mathrm{Paz}$ - constrói uma identida de embaralhada pelas próprias convençóes, a ponto de se revelar no oculta mento: Es el instante de poner cerrojo a los labios/ oir a los condenados gritar/ contemplar a cada uno de mis nombres/ahorcados en la nada.

Se o mesmo só consegue ser o mesmo permitindo-se ser o outro, aquello tan otro que es yo, Alejandra Pizarnik compreende e confessa Yo lloro debajo de mi nombre, confissão e compreensão do nombre enquanto máscara, persona. Por que o pranto? Porque a via de chegar a ser um é ser nenhum. $O$ nombre leva ao número, o diferente à diferença. A fornicação de nomes produz numerosos funerais. Coerente e implacável, Pizarnik situa sua escritura nos marcos da mais aguda modernidade. Com efeito, no processo da individuação à indiscriminação, o sujeito moderno vai se definindo como massa anônima sem nombre, figuras de cera los otros y sobretodo yo que soy más otra que ellos. Anonimia, anomia, ausência de lei, que é ausência de harmonia. Daí que, para se firmar, a cultura moderna precise negar a natureza:

Se prohibe mirar el césped

Maniqüí desnudo entre escombros. Incendiaron

la vidriera, te abandonaron en posición de

ángel petrificado. No invento: esto que digo

es una imitación de la naturaleza, una naturaleza muerta. Hablo de mí,

naturalmente.

Mas não se trata apenas de negar a natureza. A idéia de uma imagem infalivel nos levou à falência das imagens. Como observa Elio Grazioli, perdida a origem, perdida a profundidade, perdido o valor, nenhuma nostalgia, nenhuma reação a não ser a radicalização das mesmas armas contra as quais se combate, a imagem de terceiro grau contra a de segundo grau, al superfície contra a superficialidade, a hiper-realidade contra a irrealidade. Alejandra Pizarnik compreende, radicalmente, que deve usar a morte contra a morte. A morte não é uma imagem da poesia: ela é a poesia. Só o cadáver é um.

Nos seus escritos, a lógica do simulacro age por defesa e reparo, no duplo sentido destas duas palavras, erguendo obstáculos que desenham, ao mesmo tempo, os espaços de identidades possíveis. Estes tópicos são dois. $\mathrm{O}$ primeiro pertence à esfera pública: é o muro. $\mathrm{O}$ segundo, aos hábitos privados: a máscara do rosto, palavras que em Alejandra, como antes dela em Artaud, oscilam livremente com um nome-chave : manequim.

Estes objetos-não-objetos (o muro, o rosto, o texto), que estão-ñ̃oestando e são-não-sendo, criam, correlativamente, o sujeito de um saber deslocado e ubíquo, que, só ao ser elevado à potência infinita, encontra, paradoxalmente, a unidade desejada, tal como a Hécate de Ana Cristina César. Ârtemis, Hécate, Diana são divindades das margens que (para dizê-lo com Jean Pierre Vernant) operam sempre com o duplo poder de preparar as passagens entre o selvagem e o civilizado, preservando estritamente as fronteiras, ainda quando estão sendo atravessadas. Elas instituem ritos outros e liberadores, acompanhando seus fiéis até a outra margem, em território firme do Mesmo. É provável que para muitos a invisibilidade da lei se confunda com sua inexistência. Para refutar o argumento, vale lembrar as palavras de Oetavio Paz no prefácio ao livro de Alejandra: a árvore de Diana nॉ̆o 6 um corpo que se possa ver: $d$ um objeto (animado) que nos deixa ver além, um instrumento natural de viafo. Convençĩo que tende ao espontâneo. 
Nova lei. $\overline{\mathrm{E}}$ possível, portanto, resgatar um sentido crítico (político) nesta atitude avessa à indigência simbólica da indústria cultural. Em virtude dela, la muchacha halla la máscara del infinito/y rompe el muro de la poesía. Com efeito, nos textos de Alejandra Pizarnik, rosto e muro se equivalem (não apenas em função do jogo bretoniano do um no outro) mas porque a invasão do maior (o público) pelo menor (o íntimo) é, para Pizarnik, ensaio de novo pacto de cidadania. Há, assim, uma impregnação de muros e rostos, que definem uma atitude de resistência e recusa. Avivando o ser, mercê da negatividade, Pizarnik quer transmutar a relação da consciência com as coisas inertes, longínquas, porque a verdadeira morte está no saber absoluto. Em compensaç̃o, ela ensaia uma nova liberdade, uma eternidade possível para a consciência, impugnando, assim, a naturalidade dos limites para enfrentar o impossivel infinito. É por essa via que o saber de Pizarnik mantém laços com o savoir passionel, a esperança de Yves Bonnefoy.

Como o muro, a máscara oculta, veda. Como a máscara, o muro é anônimo, nulo: es mero muro es mudo mira muere. Se o muro tem segredos, o temor acumula palavras, poemas, que são silêncio, grau zero dos elementos: el viento y la lluvia me borraron/como a un fuego, como a un poema/ escrito en un muro. $\mathrm{O}$ que resta então? Aprender a dormir na memória de um muro. Ali faz solidão e as palavras se suicidam. Recapitulemos. O sujeito, como vimos, é nome. É rosto. Mas perdido el nombre que me llamaba/ su rostro rueda por $m i$. Eu=nombre; eu=rostro; $\mathrm{eu}=$ muro; eu mudo. Me muro, memoro, me muero. Eis o programa de um poema importante de Los trabajos y las noches:

\section{Nombrarte}

No el poema de tu ausencia,

sólo un dibujo, una grieta en un muro,

algo en el viento, un sabor amargo.

De Yves Bonnefoy (poeta admirado, traduzido) a Pizarnik (e dela à Reconstrução do fato, de Edgardo Russo), a lei (o nomos) se traslada. De um a outro, o trabalho da poesia é nomear o que se perde. Nomear é voltar-se ao desconhecido. Nomear - diz o poeta francês, pensando em Rimbaud - parece permitir uma participação imediata e mais do que cega na chama violenta - a salamandra - daquilo que é. Entretanto, o princípio da identidade negativa restringe o ser a um pequeno número de entes: o novo, o monstro, o marginal, o criminoso, o doente, o poeta. A premissa baudelairiana de partir ao desconhecido para encontrar o novo (re-articulada pelo barco bêbedo) permite a Pizarnik explicar con palabras de este mundo/ que partió de mi un barco llevándome. Nomear é restituir o reprimido, função política do nome, que torna a adquirir a materialidade daquilo que foi silenciado. Por isso Alejandra se identifica com o autor de Salamandra, na medida em que Octavio Paz pretende nomear no lo que dices, lo que olvidas.

Deslizamentos do ser e dos sentidos, os nomes não dizem o que dizem. Para alcançarem, portanto, um sentido é preciso deslocá-los, encontrar el lugar en que se forma el silencio, descobrindo, ainda, que cada palabra dice lo que dice y además más y otra cosa. Em busca desse outro suplemento, Alejandra perde "La última inocencia":
Partir: fenda viva, fim de linha. Extrair a pedra da loucura. As pedras que dormem ria garganta são uma tribo de palavras mutiladas que aí buscaram asilo. $\dot{E}$ a pedra que Van Gogh carregou pela vida afora, pendurada no pescoço, a pedra do pintar sem saber por quê nem para onde, como nos disse Artaud. Ora, Alejandra admite: había que escribir sin para que,/ sin para quien, ou, em palavras de Freud a Fliess, a única e autêntica punição para quem escreve é ler: a leitura considerada e praticada como uma forma de suicídio.

Em seu Livre de lectures, Marthe Robert anota que o leitor inveterado, - verdadeiro, aquele que lê até morrer, não denuncia apenas uma perversão extremada do espírito mas compele a literatura a explicar sua dupla natureza, que lhe faz secundar secretamente a morte, mantendo a feição de representar o vivo. A leitura como um outro absoluto, como um suicídio diferido.

Para escrever, Alejandra Pizarnik lê. Em 1965, por exemplo, ela traduziu o pós-escrito de Van Gogh le suicidé de la société, fragmento impregnado por uma obsessão (de Van Gogh, de Artaud e, através deles, de Alejandra): la de hacer que los objetos sean otros, la de atreverse al fin a arriesgar el pecado de lo otro.

O nome, sabemos, é imaterialidade presente que remete a uma certa materialidade hipotética: a do processo da memória. Ora, Alejandra descobre, em sua escritura em segundo, terceiro grau, que o poema diz o que diz e ademais (sobretudo) outra coisa. Descobre, por exemplo, que, para se libertar dessa obsessão, Artaud viajou pela linguagem, aproximando dépouiller (despojar-se) de s'épouiller, arrancar os piolhos. Alejandra traduz: "de todos los pintores Van Gogh es aquel que más profundamente nos despoja, y hasta la trama, pero como quien se despiojaría de una obsesión". Mesmo Aldo Pellegrini, o pioneiro surrealista dos anos vinte, ao publicar a versão integral desse texto de Artaud em 1971, irá acatar a lição de Alejandra, decerto porque compreende que, em seus exercícios hipertextuais, Alejandra Pizarnik fala com sua voz e com a voz que a precede: hablo con la voz que está detrás de la voz y emito los mágicos sonidos de la endechadora. Como ela mesma observa em seu ensaio "El verbo encarnado", ler o último Artaud em tradução é como olhar reproduções de quadros de Van Gogh. Como recuperar a corporalidade da linguagem, a marca respiratória do poeta? Vejo a chave numa citação de Marcel Granet, transcrita pela própria Alejandra e que resume a eficácia perseguida por Artaud (e por ela): Savoir le nom, dire le mot, c'est posséder l'être ou créer la chose. Toute bête est domptée par qui sait la nommer. $\mathrm{O}$ enunciado é inequívoco; a enunciação, porém, é cindida: mi voz no, mis voces. Essse ensaio polifônico na escritura de Pizarnik se anuncia em deslizamentos paronomásicos: partir o nome, a partir do nome. Assim a voz se transmuta. Te transmite. Una llamada, una llamarada, un llamamiento. Te 
suscito, te resucito. Las ofensas fantásticas, las culpas fantasmas. Tudo isso é mi día, mi vía. Alejandra vê, argutamente, que a auto-reflexividade de sua obra, esse nombrarte, que é perpétuo e infindável nombrarse, desenha uma poesia da transgressão, em que a promessa da origem constantemente retrocede. Quanto mais excrescente e ornamental for o objeto, tanto mais deserto e degradado o processo: pura estopa: (pura estepa tu memoria). Na medida em que o sublime se concebe como articulação de uma loucura que paira no discurso e que é expulsa da experiência, quando veo un templo, tiemblo. Se lembramos que, para Alejandra, o tremor era manifestação primeira do ser, exibição de um erotismo espasmódico, o deslizamento vale: entrada do templo, entrada no tempo. Um tremor, uma angústia fadados ao infinito porque apoiados na transgressão dos limites: representar o irrepresentável, ser nombre, ter pátria, funções, espaços, privativos do homem.

Só um lugar não-lugar poderia acolher um objeto não-objeto: a angústia do verdadeiro espaço é o único programa da poesia, sempre afastada da morada possível. O poeta vive en la sed siempre, a soif si folle de Rimbaud: $\overline{\mathrm{E}}$ essa sua morada. (É curioso observar como em Alejandra o lugar da poesia, a morada, não é substancial mas mero atributo: ausência de cor no céu lilás, esfera morada. Vale, assim, pensar em poemas como "Fuga en lila" ou o próprio "Moradas", onde as ondas violáceas do céu (Artaud) provocam rumor a lila. Pensar nos golpes en la tumba como ecos das asas dos corvos de Van Gogh, soando nos ouvidos de Artaud como címbalos funéreos)(¿ Adónde conduce esta escritura? A lo negro, a lo estéril, a lo fragmentado. $O$ ideal do negro, nos relembra Adorno, além de ser índice poderoso de abstração, consolida a resistência e a dissonância, únicos recursos para a criação do novo, na medida em que, na terra de ninguém do mundo moderno, nenhum prazer habita na harmoniosa duplicação do já existente. Risco das muitas vozes: anular-se em monocorde única voz, a do saber absoluto. É necessário, portanto, suspender as normas (os nombres) para a emergência do desconhecido: y no hubo más un afuera $y$ un adentro. Nadie estaba escuchando el lugar porque el lugar no existía. 